RUNNING HEAD: Clinical Psychological Science and COVID-19

\title{
Mental Health and Clinical Psychological Science in the Time of COVID-19: Challenges, Opportunities, and a Call to Action
}

June Gruber1, Mitchell J. Prinstein2, Jonathan S. Abramowitz2, Anne Marie Albano3, Amelia Aldao4-5, Jessica L. Borelli6, Tammy Chung29, Lee Anna Clark7, Joanne Davilas, Erika E. Forbes9, Dylan G. Gee10, Gordon C. Nagayama Hall11, Lauren S. Hallion12, Stephen P. Hinshaw13-14, Stefan G. Hofmann15, Steven D. Hollon16, Jutta Joormann10, Alan E. Kazdin10, Daniel N. Klein8, Annette M. La Greca28, Robert W. Levenson13, Angus W. MacDonald17, III, Dean McKay18, Katie A. McLaughlin19, Jane Mendle20, Adam Bryant Miller2, Enrique Neblett21, Matthew Nock18, Bunmi O. Olatunji16, Jacqueline B. Persons22, Jonathan Rottenberg23, David C. Rozek24, Jessica L. Schleider8, George M. Slavich25, Bethany A. Teachman26, Vera J. Vine9, \& Lauren M. Weinstock27

1 Department of Psychology and Neuroscience, University of Colorado Boulder 2 Department of Psychology and Neuroscience, University of North Carolina at Chapel Hill 3 Vagelos College of Physicians and Surgeons, Columbia University

4 Teachers' College, Columbia University

5 Department of Psychiatry, Mount Sinai Hospital

6 University of California, Irvine

7 University of Notre Dame

8 Stony Brook University

${ }_{9}$ Department of Psychiatry, University of Pittsburgh

10 Department of Psychology, Yale University

11 Department of Psychology, University of Oregon

12 Department of Psychology, University of Pittsburgh 


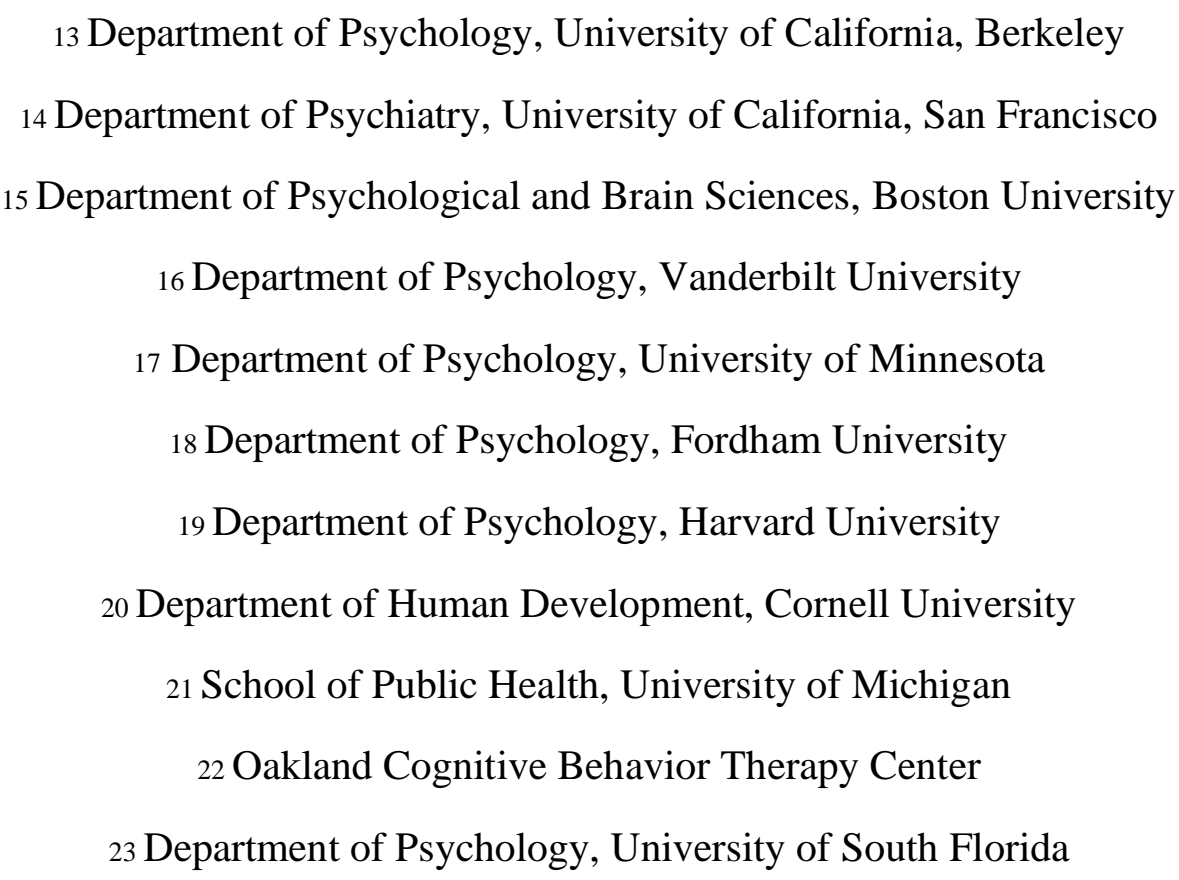

24 UCF RESTORES and Department of Psychology, University of Central Florida

${ }_{25}$ Cousins Center for Psychoneuroimmunology and Department of Psychiatry and Biobehavioral

Sciences, University of California, Los Angeles

26 Department of Psychology, University of Virginia

27 Department of Psychiatry, Brown University

28 Department of Psychology, University of Miami

29 Institute for Health, Healthcare Policy and Aging Research and Department of Psychiatry;

Rutgers, The State University of New Jersey

Corresponding Authors: June Gruber, University of Colorado Boulder, Department of Psychology and Neuroscience, 345 UCB Muenzinger D321C, Boulder, CO 80309-0345; 510410-3822; june.gruber@ colorado.edu; Mitch Prinstein, UNC Department of Psychology and Neuroscience, 240 Davie Hall, CB 3270, Chapel Hill, NC 27599-3270, 919-962-3988, mitch.prinstein@unc.edu. Authorship Note: All author names for the full manuscript are listed alphabetically by last name after the corresponding authors. 


\begin{abstract}
COVID-19 presents significant social, economic, and medical challenges. Because COVID-19 has already begun to precipitate huge increases in mental health problems, clinical psychological science must assert a leadership role in guiding a national response to this secondary crisis. In this paper, COVID-19 is conceptualized as a unique, compounding, multidimensional stressor that will create a vast need for intervention and necessitate new paradigms for mental health service delivery and training. Urgent challenge areas across developmental periods are discussed, followed by a review of psychological symptoms that likely will increase in prevalence and require innovative solutions in both science and practice. Implications for new research directions, clinical approaches, and policy issues are discussed to highlight the opportunities for clinical psychological science to emerge as an updated, contemporary field capable of addressing the burden of mental illness and distress in the wake of COVID-19 and beyond.
\end{abstract}

Keywords: Clinical Psychological Science; Clinical Psychology; Mental Health; Treatment; Coronavirus; COVID-19; Pandemic

\title{
Significance Statement
}

Clinical psychological science must lead a national response to address mental health issues following COVID-19. This article highlights urgent challenges to confront, and timely opportunities to contemporize a field to better address mental health issues now and long after. The article concludes by discussing implications for new research directions, clinical approaches, and policy issues. 


\section{Mental Health and Clinical Psychological Science in the Time of COVID-19:}

\section{Challenges, Opportunities, and a Call to Action}

COVID-19, the illness produced by the severe acute respiratory syndrome coronavirus 2 (SARS-CoV-2), has been associated with some of the greatest social, economic, and medical challenges of the 21st century. Between November 2019, when the outbreak began, and early May 2020, over 4.6 million people worldwide tested positive for infection with the virus, and more than 300,000 have died. Understandably, the first response phase focused on reducing infection rates, thereby preserving hospital resources (i.e., "flattening the curve") (Adhanom Ghebreyesus, 2020; Gruber \& Rottenberg, 2020). As such, the initial contribution of clinical psychological science was attenuated relative to such fields as virology, epidemiology, and public health. Increasingly, however, it is becoming clear that the pandemic confers grave and potentially long-term mental-health implications for the nation. The toxic psychosocial stressors that the pandemic has created (e.g., physical risks, daily disruptions, uncertainty, social isolation, financial loss, etc.) are well known to affect mental health (and thereby also physical health) adversely, and collectively encompass many characteristics that have been identified as having the greatest negative effects. Moreover, preliminary evidence suggests that the virus has direct behavioral-health sequelae and exacerbates existing psychopathology (Ghebreyesus, 2020). Accordingly, the field of clinical psychological science must play a leadership role in guiding a national response for the foreseeable future.

There are three ways in which the COVID-19 pandemic may be particularly, and perhaps uniquely, detrimental to mental health. First, it is long term and widespread, with an uncertain end date; the stakes are high, the disruption to daily routines is severe, and the loss of resources to meet both immediate (e.g., food, cleaning supplies) and future needs (e.g., due to unemployment) is significant. 
Second, the COVID-19 pandemic is a multidimensional stressor, affecting individual, family, educational, occupational, and medical systems, with broader implications for the macrosystem, as it exacerbates political rifts, cultural and economic disparities, and prejudicial beliefs. Concerns regarding interpersonal disruption may be particularly relevant for understanding its psychological effects and both physical and psychological outcomes. Reduced social interaction is a notable risk factor for mental-health difficulties and the negative impact of loneliness on mental and physical health is well-documented (Cacioppo, Grippo, London, Goossens, \& Cacioppo, 2015). Many individuals are facing serious illness_-and thus, prolonged separation or even death — of loved ones, made even more difficult by interruptions in typical modes of grieving (e.g., funerals, spending time with family, sitting shiva, religious services), or by ongoing concerns regarding one's own or one's family members' safety. Social disruptions during COVID-19 also include role confusion and conflict: many parents are serving as both home-school teachers and care providers while also maintaining occupational responsibilities. These role changes thus increase parental stress and fatigue which, in turn, result in lower parenting satisfaction, self-efficacy, and distress tolerance (e.g., Kinnunen \& Mauno, 1998). Strict stay-at-home guidelines also confer risk for sustained exposure to many interpersonal sources of adversity (e.g., marital discord, parent-child conflicts, interpersonal threat and deprivation, parental psychopathology, addictive behaviors, unemployment and economic instability, and lack of social support), many of which are known risk factors for child abuse (Brown, Cohen, Johnson, \& Salzinger, 1998; Stoltenborgh, Bakermans-Kranenburg, \& Van Ijzendoorn, 2013) and the onset of psychopathology (McLaughlin et al., 2012).

Third, the protections needed to safeguard against infection necessarily, but ironically, block access to protective factors that are known to reduce the effects of stress (e.g., enjoyable distractions, behavioral activation, social relationships) because they are difficult to employ 
while adhering to stay-at-home and social-distancing mandates. The lack of protective factors may be especially marked among socially isolated older adults who also are among the most vulnerable to the virus.

This paper, therefore, aims to highlight the most urgent areas to address, and suggest research directions, clinical approaches, and policy issues that need attention. Although numerous scientific fields, and psychological sub-disciplines, will need to be involved to address a myriad of inter-related relevant issues, this paper focuses specifically on necessary contributions from "clinical psychological science," a subfield within mental health disciplines that reflects "a broad intellectual commitment to the importance of empirical research, its integration with clinical practice, and the central role that science must play in the training of clinical psychologists" (Oltmanns \& Krasner, 1993)1. Extant findings are used to articulate briefly the unique mental health issues across developmental age levels that are likely to result from COVID-19. Next, acute challenge areas that are likely to emerge during the course of the pandemic are considered. A path forward is then discussed, highlighting new areas for discovery and potential paradigm shifts from traditional models of clinical psychological science implementation. It may be that the COVID-19 pandemic will prompt changes to mental health fields that have long been needed - only now, the changes are required to survive. In short, this paper has two main goals: (1) to leverage what is known within clinical psychological science to address the enormous U.S. mental-health needs exposed by COVID-19 and (2) to highlight what is unknown, perhaps prompting reforms to practices that are overdue for an update.

\section{Psychological Impacts of COVID-19 Across the Lifespan}

1The term developed over a period of years (1964 to 1991) that saw an increasing belief among clinical psychologists that there was a "fundamental incompatibility of the roles of scientist and professional within one individual" (p. 1071; Albee, 1970). In contrast, a subgroup of clinical psychologists believed that "the scientist and the practitioner not only can be reunited but must be in order to continue the profession of clinical psychology as a viable, useful, and unique one in society." (Oltmanns \& Krasner, 1993) 
Within the U. S., government officials and the popular media have begun to recognize the mental health crises that are likely to follow the immediate physical threat associated with the COVID-19 pandemic. Substantial research suggests that these needs can now be predicted from theoretical models regarding psychopathology risks and articulated with some clarity and detail. This section provides a brief review of this literature to highlight unique risks applicable to different developmental stages, including childhood, adolescence and young adulthood, middle adulthood, and older adulthood.

Childhood. Children's emotional/behavioral responses to COVID-19 are likely to result more from significant disruptions to typical roles and daily routines than an appraisal of the health and economic concomitants of the pandemic.Government-mandated school closures affected more than 45 million children in the U.S. as of this writing May 2020. Worldwide, this included school closures in 138 countries, affecting approximately $80 \%$ of school-aged children (Van Lancker \& Parolin, 2020). In combination with changes in parents' and caregivers' schedules or availability, this process has been the most disruptive, prolonged shift to children's daily lives in many decades, scrambling their familiar routines and reducing the number of adult and peer resources available to them. Indeed, schools are a major point of access to mental health resources for children (Merikangas et al., 2011) and serve as gateways for identification and referral to specialty mental health providers (Farmer et al., 2003). Importantly, developmental and mental health risks associated with the vast societal changes triggered by the COVID-19 pandemic are likely to be felt disproportionately by children living in families with lower economic resources and/or experiencing high levels of adversity prior to the pandemic.

Adolescence. Many forms of psychopathology increase in severity and/or prevalence during adolescence. COVID-19 pandemic-related disruptions are likely to exacerbate developmental vulnerabilities to a wide range of internalizing, externalizing, and health-risk 
behaviors. Numerous factors may explain the increased risk to adolescents, including an increased exposure to parents' mental health problems, a loss of important "rite of passage" milestones (e.g., senior prom, graduation), uncertainty about the future, and a loss of autonomy. Yet perhaps the most important impact on adolescent lives will be the significant disruption to peer experiences that are critical for youths' emotional, moral, behavioral, and identity development (Prinstein \& Giletta, 2016). During the COVID-19 crisis, many adolescents have increased their already remarkably frequent use of digital media to compensate for the loss of inperson social interactions, yet emerging research suggests that digitally mediated social interactions may be distinct in form and psychological function from face-to-face experiences (Prinstein, Nesi, \& Telzer, 2020). Separated from their peers, adolescents also will miss chances to engage in reward-seeking behaviors that characterize this developmental period, and that often enable opportunities for growth and exploration (Forbes \& Dahl, 2012; Tezler, 2016).

Young Adulthood. The combination of mental-health, financial, and social changes during COVID-19 also poses unique challenges for young adults (e.g., Arnett, 2004). Although some young adults will experience many of the same challenges as adolescents with regard to missed rites of passage and disrupted social lives, others who return to living with parents may find a stalling or regression of key developmental milestones, including their independence in sexual relationships, expression of their sexual and gender identity, and ability to engage (or not) in religious, political, or other pursuits of their choice. This can result in unprecedented role confusion if forced into an unwelcome adolescent role (e.g., back living with family after a period of independence) or an adult role for which they feel unprepared (e.g., economic selfsufficiency). In addition to the immediate financial constraints of a tenuous economy and high unemployment, long-term vocational and social growth may be narrowed through curtailed education, limited ability to travel, difficulty obtaining vocational training or experience, and a 
slow ramp-up of the economy as restrictions begin to ease, with limited employment opportunities for entry-level workers.

Middle Adulthood. Adults in the middle-adulthood lifespan phase face unique and compounding economic and social stressors during the COVID-19 crisis that put them at heightened risk for mental health challenges. These include economic stressors tied to sudden unemployment or furloughs, and salary cuts that threaten their current and future economic stability. Middle-aged adults with children may also face abrupt role shifts as they transition to full-time homeschool teachers with little to no preparation, while also juggling work demands with little childcare support, which can quickly cause parental burnout and mental exhaustion (Manjoo, 2020). In addition to the immediate financial and caregiving stressors during COVID19, those middle-aged adults with living parents may additionally face increased anxiety and worry about the health and ability to care for (or even visit) their parents while physicaldistancing guidelines are enforced.

Older Adulthood. Older adults are uniquely vulnerable during COVID-19, both physically and psychosocially. Older adults may have a heightened susceptibility to infection and its adverse consequences, and they may experience a loss of usual social support, such as family members visiting (Garnier-Crussard et al., 2020). This abrupt physical threat and loss of social resources may increase risk for loneliness, isolation, and depression among older adults (e.g., Armitage \& Nellums, 2020). Research during the 2002-2004 SARS outbreak documented that greater levels of stress, anxiety, and social isolation among older adults were associated with higher suicide rates (Chan et al., 2006; Yip et al., 2010). Particularly vulnerable are older adults with dementia, which interferes with full cognitive understanding of the threat of the virus and hampers remembering to use safety behaviors (e.g., hand washing, wearing a mask when necessary). Family members providing care for people with dementia (over 16 million in the 
U.S. alone; Alzheimer's Association, 2020) already are highly vulnerable to mental health problems (Schulz, O'Brien, Bookwala, \& Fleissner, 1995). For them, sheltering in place can add to social isolation, reduce access to external resources, and increase burden. Finally, for older adults living in congregated nursing-home facilities, risk of infection spread can be dramatically heightened (Wang et al., 2020).

\section{Psychological Sequelae of COVID-19}

The COVID-19 pandemic introduced a complex worldwide stressor, and the strategies used to reduce physical health threats ironically may undercut critical protective factors known to buffer the negative effects of psychological stress. It is thus reasonable to assume that the pandemic will be associated with a substantial, sustained, and potentially severe "mental health curve" that, like the prevalence of the virus itself, will also need flattening given alreadyinsufficient mental health resources in the U.S. Ideally, federal and state resources would be allocated to address mental health needs with the same vigor and attention that has been dedicated toward physical health threats. Yet this response seems unrealistic in light of a long history of inadequate attention to, or funding for mental health; thus, it is incumbent upon clinical psychological scientists and practitioners to conceive of innovative approaches to meet the increased burden of mental illness. This section discusses a model for understanding the psychological sequelae of COVID-19-related phenomena; briefly reviews preliminary, emerging research confirming an increased rate of mental health distress; and then discusses specific presentations of psychopathology that may deserve special attention.

Stress and Loss of Protective Factors. Increased psychological difficulties following the COVID-19 pandemic are likely to result from stress, defined as the physical and psychological responses that occur when situational demands outweigh one's real or perceived resources to address them (Brooks et al., 2020; Lazarus \& Folkman, 1984; Monroe, 2008). As noted earlier, 
this complex stressor is characterized by great uncertainty, life-threatening conditions, prolonged exposure to anxiety-inducing information, and losses (e.g., of loved ones, financial security, daily routines, perceived control, and social roles), as well as actual physical threat. COVID-19 may represent a "perfect storm" of stress with high potential for adverse mental health consequences. Psychobiological models have described clear associations between stress, the activation of brain systems (e.g., amygdala) that process fear and threat, and the release of cortisol, epinephrine, and norepinephrine into the bloodstream (e.g., O’Donovan, Slavich, Epel, \& Neylan, 2013). These responses are adaptive in the short term, mobilizing needed resources to address acute threats. When prolonged, however, these responses can take a toll on the body known as allostatic load (McEwen \& Stellar, 1993), which negatively affects the brain (e.g., hippocampus), cardiovascular system (e.g., high blood pressure), and immune system (e.g., increased inflammation) (McEwen \& Wingfield, 2003). Inflammation, in turn, increases risk for psychopathology and related physical health problems (Furman et al., 2019; Slavich, 2020). Populations experiencing increased stress due to COVID-19 are thus likely to suffer from a wide range of mental as well as physical health difficulties.

Several literatures support this supposition. For instance, work on highly disruptive or lifethreatening natural and human-made disasters suggests markedly high risk for psychopathology following stress exposure, including increased internalizing and externalizing symptoms across age groups (Bonnano et al., 2010; La Greca, Silverman, Vernberg, \& Roberts, 2002; Wang et al., 2013). These adverse mental health impacts are most prevalent in vulnerable populations (e.g., those at socioeconomic disadvantage, minority groups; Tang et al., 2014), and various risk factors (e.g., temperamental fear, neural reactivity to emotional stimuli) are associated with more post-disaster symptoms (Kujawa et al., 2016; Meyer et al., 2017). For some individuals, these effects persist long after the disaster has passed (Bonano et al., 2010). 
Early, descriptive data examining mental health concomitants of COVID-19 also support this prediction. In an early-2020 sample of 1,200+ Wuhan-area nurses and physicians, relatively high prevalence estimates (i.e., 12\% 15\%, and 36\%) of moderate-to-severe levels of anxiety, depression, and general distress, respectively, were reported (Lai et al., 2020). The pandemic is also already affecting national mental health in countries that were hit early; for example, there have been sharp rises in anxiety and depression in China (Gao et al., 2020). A similar pattern is likely to occur following COVID-19 more globally, especially among vulnerable populations, with the severity and duration of mental health difficulties being proportionally greater as a function of the severity and duration of the stressors. In this context, there are several areas of psychopathology that are most likely to result from COVID-19. Five of these areas are addressed in the sections that follow, although there is insufficient space to do full justice to them all.

Anxiety and Depression. Anxiety and depressive symptoms are likely to increase during the COVID-19 pandemic, resulting in greater vulnerability to psychological distress in the population at large and more individuals with diagnosable psychiatric disorders. This supposition is supported by data from the 2008 U.S. financial crisis, which suggested that chronic stress acutely increased risk for internalizing disorders (specifically, depressive, anxiety, and panic symptoms; Forbes \& Krueger, 2019). This possibility is also supported by contemporary models that articulate how stress affects psychological and biological systems associated with anxiety and depression (e.g., Slavich, 2020). For instance, extant research reveals that psychological stressors increase emotional reactivity and reliance on maladaptive emotion-regulation strategies that are known to exacerbate risk for internalizing symptoms (e.g., Nolen-Hoeksema, Wisco, \& Lyubomirsky, 2008; Segerstrom et al., 2000). COVID-19 related stressors, such as social-distancing mandates, may also reduce access to regular social interactions that are recognized as an important process for promoting psychosocial resilience and overall wellbeing (Cohen, 2004; Hofmann, 2014; Slavich, 2020). 
The COVID-19 pandemic is also likely to precipitate substantial increases in depression. Depression is generally theorized as an abnormal response to loss, and the pandemic is likely to engender loss experiences in several life domains. Most notably, COVID-19 will lead to the death of loved ones for many individuals, with such deaths being relatively sudden and otherwise unexpected. In addition, the pandemic is leading to losses in social connectedness, daily routines, social roles, jobs, and financial stability. COVID-19 also directly affects other risk factors for depression, such as emotion regulation and coping (Gross \& Jazaieri, 2014) and may interfere with many protective forms of responding, such as seeking of social support and use of problem-focused coping strategies (e.g., thinking of various ways to solve a problem, selecting one, and taking action) (Compas et al., 2017; Hofmann, Sawyer, Fang, \& Asnaani, 2012). At the same time, social isolation and ongoing media coverage focusing on social-environmental threat may result in increased rumination and worry that drive biological processes such as inflammation that increase risk for depression (Slavich \& Irwin, 2014). Social isolation and stay-at-home orders also may interfere with the ability to experience positive affect, apply social strategies for regulating affect, and use rewarding experiences to offset negative emotions. Given the importance of social connection and belonging for regulating positive affect for resilience to depression and resilience in general, COVID-19 may be particularly likely to increase risk for depression.

Although anxiety and depression overlap both temporally and in terms of phenotypic presentation, anxiety is generally considered a primary response to threat or uncertainty, whereas depression is typically conceptualized as an abnormal response to loss. Notably, the COVID-19 pandemic is a complex, multifaceted stressor that includes elements of threat, uncertainty, and potential loss. It is well known that not all individuals who experience major life stress develop affective disorders, with cognitive and emotional responses playing a critical role in determining whether anxiety or depression follows such stress (Aldao \& Nolen-Hoeksema, 2010). Therefore, it 
will be important to pay attention to exaggerated perception of threat (which have been linked to anxiety) and loss (which have been linked to depression). It will also be important to ensure that the behaviors required to ensure physical safety, such as avoidance (e.g., of other people and public spaces) and vigilance (e.g., scanning the body for signs of disease), do not have the unintended consequence of increasing risk for the onset, exacerbation, or relapse of these two disorders.

Traumatic Stress Reactions. Acute Stress Disorder (ASD) and Posttraumatic Stress Disorder (PTSD) are trauma- and stressor-related disorders that may occur at any age, and may result from direct exposure to a traumatic event involving actual or perceived life-threat, as well as from repeated or extreme exposure to aversive details of a traumatic event (American Psychiatric Association, 2013). ASD symptoms are shorter in duration (3 days to 1 month) than for PTSD (at least 1 month) but, for both, symptoms include intrusion (e.g., nightmares), negative mood or cognitions, avoidance, and arousal (e.g., hypervigilance, insomnia).

Traumatic stress symptoms are likely to increase as a result of the COVID-19 pandemic because the multiple stressors that characterize it, including the threat to personal safety and security, significant life disruption, loss of loved ones and of financial resources, and disruption and erosion of interpersonal support systems, have been implicated in the development or maintenance of ASD and PTSD symptoms (e.g., Bonanno et al., 2010). In fact, the disaster mental-health and medical-trauma literatures are pertinent to understanding the mental health impacts of COVID-19 which has exposed many individuals to medically-related traumatic events associated with symptoms of ASD and PTSD, such as the sudden death of a loved one, near death experiences, and life-threatening medical procedures (e.g., Hatch et al., 2018). Increased symptoms of traumatic stress (e.g., arousal, negative intrusive thoughts) are likely to occur in the general population, potentially fueled by media exposure to traumatic aspects of COVID-19 (Gao et al., 2020). Although such symptoms may reflect a normative response to an 
unusually stressful situation, such symptoms are of substantial mental health concern when they are severe, persistent, and interfere with functioning.

Vulnerable populations in high-impact disasters, such as first responders and healthcare providers (Bonanno et al., 2019; Norris et al., 2002), as well as other essential workers, are likely to be at risk for developing subclinical or clinical levels of ASD or PTSD in the COVID-19 pandemic. Healthcare providers and first responders may be exposed to extreme stressors, often referred to as secondary traumatic stress (Greinacher, Derezza-Greevan, Herzog, \& Nikendei, 2019), such as the sudden death of patients and moral decision-making regarding for whom to provide lifesaving intervention (Griffin et al., 2019). First responders and essential workers also provide direct services to individuals with COVID-19 or have increased exposure to the general public, thereby increasing their own COVID-19 risk. Further, these vulnerable groups are advised to self-isolate away from family (Ellis, 2020), thereby restricting social support, and further increasing their risk of traumatic stress reactions (e.g., Kaniasty \& Norris, 2008; La Greca, Silverman, Lai, \& Jaccard, 2010). Family members of first responders also may be at elevated risk for traumatic stress reactions, as they fear for loved ones' safety (e.g., Duarte et al., 2006). Furthermore, elevated rates of PTSD have been observed among women and children and among disadvantaged minority groups in the aftermath of disasters (Bonanno et al., 2010; Norris et al., 2002), and are likely to emerge for the current pandemic. PTSD symptoms also confer risk for alcohol and substance use, relationship difficulties, and suicidal thoughts and behaviors (e.g., Sareen, 2014). Elevated symptoms of PTSD also commonly co-occur with symptoms of depression, which bodes poorly for recovery (e.g., Lai, La Greca, Auslander, \& Short, 2013), and complicates treatment (e.g., Cohen et al., 2010; La Greca \& Danzi, 2019).

Overall, the "good news" is that most youth and adults exposed to traumatic events recover over time, although a significant minority (15\% to $30 \%)$ continue to display elevated symptoms 
of PTSD a year or more post-disaster (Alisic et al., 2014; Bonanno et al., 2010) and will benefit from psychological interventions (APA, 2017; Cohen et al., 2010; La Greca \& Danzi, 2019). Psychological first aid (Brymer et al., 2006), widely used for short-term crisis and disaster intervention, may be important for use with people displaying traumatic stress symptoms during the COVID-19 pandemic. Increasing access to psychological treatments, such as via telehealth procedures, will be critical to address the anticipated wide-spread need for COVID-19-related mental health services for youth and adults.

Substance Use Disorders. Individuals with substance use disorders (SUDs), particularly those who smoke, vape, or use opioids, may be at increased risk for COVID-19 illness severity and even death (Smith et al., 2020; Vardavas \& Nikitara, 2020;Volkow, 2020). For some, pandemic-related stressors (e.g., job loss and financial strain), anxiety, and boredom due to extended stays at home could lead to an increase in smoking or other substance use as a way to cope with negative moods (Nagelhout et al., 2017). In this regard, in March 2020, during the initial stay-at-home weeks in the United States, a survey of adults identified an association between more frequent alcohol and cannabis use in the past week and significantly higher mental distress (Johns Hopkins COVID-19 Mental Health Measurement Working Group, 2020).

For individuals in recovery from SUD or seeking addiction treatment, the pandemic has presented unique challenges. Mandated stay-at-home orders have increased social isolation and concomitant risk for relapse for some individuals (Volkow, 2020). Specifically, staying-at-home can involve domestic stressors (e.g., intimate partner violence), which can challenge recovery efforts. These stressors, in turn, can lead to or exacerbate co-occurring mental health conditions such as depression and anxiety among individuals with SUD (Tripp, Jones, Back, \& Norman, 2019). In addition, marginalized individuals, who are homeless or imprisoned, have high rates of SUD (e.g., up to 50\% of prisoners have a SUD) (Fazel, Yoon, \& Hayes, 2017), and increased 
risk for COVID-19 infection (Volkow, 2020) are less likely to receive care during the pandemic due to service provision cut-backs (Alexander, Stoller, Haffajee, \& Saloner, 2020). In-person social support, which can provide daily structure for individuals with SUD, especially during early recovery, has shifted to virtual or telehealth platforms (Volkow, 2020). Federal guidelines have rapidly expanded to support access to and more flexible delivery of evidence-based eHealth (APA, 2020), as well as to provide needed medications to support abstinence (e.g., medicationassisted treatment for opioid use disorder) (Alexander et al., 2020) and other e-recovery support groups facilitated by psychologists in response to the pandemic (Khatri \& Perrone, 2020).

Through evidence-based eHealth interventions, psychologists are using this opportunity in a time of crisis to create structured, safe, social, virtual spaces to facilitate recovery mindfully among individuals with SUD, and to reduce stigma and harms related to substance use disorder.

Suicide. Before the onset of COVID-19, suicide already was a relatively neglected public health problem (USDHHS, 2012). The current pandemic increases the risk for suicide in at least four ways that require a far greater investment in suicide science, along with new approaches to suicide screenings and imminent risk assessments across all types of clinical care. The risk is perhaps most obviously increased in psychologically vulnerable populations through introduction of a novel, pervasive, relatively uncontrollable stressor. Those with histories of depressive symptoms, self-injury, prior suicidality, maltreatment, PTSD, substance use, and disruptive behavior disorders (particularly among youth) are especially at risk for increased suicidal thoughts and behaviors for all the stress-related reasons already discussed (Nock \& Kessler, 2006). In particular, maladaptive interpersonal patterns experienced with few opportunities to escape or distract (due to stay-at-home orders) may elevate invididuals' risk for suicide, and may intensify stressful experiences over time. Second, new at-risk populations may emerge from COVID-19, including trauma-exposed first responders, healthcare workers, 
particularly physicians (Gold, Sen, \& Schwenk, 2013) who have had to make unspeakably difficult medical-care decisions under high-pressure conditions, as well as other essential workers. Children who have experienced increased exposure to other kinds of trauma (e.g., child maltreatment; Gawęda et al., 2020) also may be at increased risk for suicidal behavior.

Third, it should be noted that suicide rates are associated closely with economic indices, with periods of recession associated with higher rates of suicide ideation, attempts, and deaths by suicide among all age and all racial/ethnic groups (e.g., Reeves et al., 2012). The worldwide economic changes associated with COVID-19 are likely to be associated with changes in a wide range of self-injurious thoughts and behaviors. Last, most theories offered to explain suicidal behavior have implicated interpersonal stress (e.g., conflict, loss) as a common factor that significantly enhances individuals' risk (Miller \& Prinstein, 2019). Reports of increased isolation, loneliness, interpersonal loss, and limited interpersonal contact thus present a uniquely high-risk period for suicide within the general population as well, requiring ongoing monitoring in the years that follow COVID-19. Unfortunately, many of the existing resources designed to address imminent suicide risk may prove less effective during or after the COVID-19 crisis. Perhaps most importantly, there may be greater reluctance to call 911 or visit a local emergency room to ensure safety from suicidal urges during the pandemic for fear of infection or out of concern that one's suicidality may overburden hospital staff who are needed to attend to COVID19 patients.

Research on suicide rates following other extremely stressful events has yielded mixed findings. For many natural disasters, suicide rates often stay stable initially (for a review, see Kolves, Kolves, \& Leo, 2013). Following natural disasters, results are mixed for longer term outcomes, with some showing an increase and others showing a decrease in suicide rates. After other extreme stressors (e.g. terrorist attacks), suicide rates have been shown to be stable or even 
to decrease, which may be due to individuals in a population "coming together" (Claassen et al., 2010) and receiving social support in doing so. As mentioned, however, an increase in social support - at least as long as social-distancing and stay-at-home orders are in effect-is not a viable option in the current disaster. Previous datapoints on pandemics are scarce, although some suggest an increase in suicide rates following the 1918 pandemic (Wasserman, 1992). Given the variation in data and extreme stressors, it is clear that clinical psychological scientists should continue to assess patients for suicidality, employ prevention strategies, and continue to collect data to inform how the COVID-19 pandemic is affecting suicide rates.

Psychosis and Other Severe Mental Disorders. Schizophrenia and bipolar affective disorder are also affected by stress-related pathways. Stress is a key factor in the emergence of psychotic illnesses (Walker \& Diforio, 1997), and repeated stress can alter the stress response itself, increasing risk for relapse and rehospitalization (Belvederi Murri, 2016; Tessner et al., 2011). The mechanism for this alteration may be that stress-related increases in cortisol release, via the HPA axis, altering related brain structures and increasing relapse (Corcoran et al., 2003). Symptom exacerbations magnify the challenges of COVID-19 for people suffering from psychotic disorders, and, as noted below, create additional burdens for family members and other caregivers. Space precludes a more lengthy discussion of how COVID-19-related threats and disruptions potentiate new delusions, exacerbate kindling, or trigger mood symptoms, but there is an acute need to understand and propagate best practices to help the most vulnerable citizens with serious mental disorders and those in their care networks.

\section{Challenges for Clinical Psychological Science Following COVID-19}

COVID-19 will produce a series of mental health challenges, yet current practices in the field of clinical psychological science will require substantial adaptation to address them. These challenges relate not only to the expected high prevalence of mental health-related problems but 
also to the various unique populations that will require services, the critical need to address significant health disparities that have long been under-addressed in most mental health fields, and changes required that are related to the contexts of service delivery. This section describes these challenges and offers recommendations from the available science regarding intervention.

\section{Who Will Need Mental Health Services?}

Although the field has a rich literature on treating psychological symptoms and distress among individuals, COVID-19 will lead to an increased need for services among populations that have been understudied. Below two populations that may need additional attention within research and practice efforts are discussed: health care workers and individuals in racial/ethnic minority groups. This section also addresses issues related to mental health stigma that may limit the number of people who receive psychological services.

Health-Care Workers. Substantial research has been conducted to understand how to address trauma among those exposed to horrific, life-threatening events, especially veterans, yet this review suggests that far less research has addressed strategies to work with health-care workers. This is a new and urgent need for the field. Such work will need to recognize that frontline health-care responders have cared for COVID-19 patients while managing significant risks to their own and their colleagues' personal health. Moreover, research on prior pandemics reveals that health-care workers may face additional public stigma and isolation because of others' perception that they may be at heightened risk for disease transmission (Williams, Gonzalez-Medina, \& Le, 2011). There are many open questions about the extent to which COVID-19 health-care workers may develop a range of emotional disorders, from "simple" burnout to depression and PTSD.

A review of extant programs offered for health-care workers indicates the content mainly focuses on basic self-care recommendations. Given strong evidence that the majority of people 
will be resilient after trauma exposure (Galatzer-Levy, Huang, \& Bonanno, 2018), along with evidence that over-treating can be harmful (Bootzin \& Bailey, 2005), for the majority of workers recommendations to bolster basic self-care (e.g., sleep hygiene, breaks from work, exercise), stress management (e.g., mindfulness), and emotional support may suffice. Further study is needed to determine how to apply the existing literature on risk for PTSD and resilience trajectories to the current circumstances. Importantly, the field needs to think broadly about the appropriate targets of interventions. For example, although it certainly makes sense to focus on deploying resources directly to health-care workers who are struggling, another, more efficient approach may be to work with hospitals and other institutions to help them create supportive environments (e.g., allowing workers to voice concerns about virus exposure or working conditions; not stigmatizing workers who express mental health needs) and to create systems that allow for more consistent monitoring of mental health concerns.

Observed mental health patterns among health-care workers during previous outbreaks may be informative (Lai et al., 2020). For example, Lancee and colleagues (2008) found that new episodes of psychiatric disorders after the SARS outbreak were positively associated with a history of previously having a psychiatric disorder and inversely associated with years of healthcare experience and the perceived adequacy of training and support. This pattern suggests a need to target resources toward COVID-19 health-care workers at higher risk, that is, those newer to the field and those with pre-existing mental health issues. Another lesson from the SARS outbreak is that a major focus of intervention for high risk COVID-19 health-care workers could include increasing access to resources for reducing daily life stress (Lung et al., 2009). In fact, health-care workers who reported mental health problems following the SARS crisis were more likely to report symptoms that were related to daily-life stress than to SARS itself (Lung et al., 2009). Of course, COVID-19 adds additional daily stressors for health-care workers, as many try 
to manage childcare, home schooling, and financial challenges on top of their extensive occupational demands. Given that those with limited training also represent a high-risk group (Lancee et al., 2008), assessing training needs of COVID-19 health-care workers will be crucial. For example, the National Ebola Training and Education Center (NETEC) was established in response to the Ebola outbreak to increase health-care workers' competency to deliver effective care to infected patients (Kratochvil et al., 2017). The NETEC also includes training in behavioral-health considerations for staff that may be relevant to the current pandemic.

In all cases, interventions for health-care workers must consider cultural responsiveness, as there will be no unitary solution that works across contexts and populations. That is, different needs may arise as a function of race and ethnicity. For instance, given rising bias against Asians in the U. S., health-care workers with Asian or Asian-American identities may have to navigate increased discrimination from patients and/or co-workers that adversely affects their mental health. Further, subcultures exist within health-care environments, and different professions may require distinct types of supports (e.g., physicians and nurses showed different post-SARS symptoms; Lung et al., 2009). Continuously and persistently monitoring mental health will be critical to optimizing care for health-care workers.

Members of Marginalized Racial and Ethnic Groups. The COVID-19 pandemic is disproportionately affecting members of marginalized racial and ethnic minority groups and those from lower SES backgrounds. Indeed, the pandemic has the potential to widen racial/ethnic and socioeconomic disparities in health and life expectancy that have steadily grown in recent decades (Singh \& Siahpush, 2006). Emerging evidence indicates stark racial/ethnic disparities in the impact of COVID-19 in the U.S., with notably higher rates of illness and mortality among Black and Latinx people (Zephyrin et al., 2020). Although similar data on infection and mortality rates as a function of SES are limited, the risks may be higher for people with low SES. Factors 
that contribute to a higher probability of contracting the illness include high population density, crowding, reliance on public transportation, and employment in low-wage jobs that are considered essential during even the most intense period of physical distancing and social isolation, such as transportation, production, and food and grocery services (Soloman, Maxwell, \& Castro, 2019). Black, Latinx, and people of low SES are also more likely to have pre-existing conditions that exacerbate risk for serious COVID-19 illness and mortality once infected, including hypertension, obesity, diabetes, and cardiovascular disease (Adler \& Rehkopf, 2008). These groups are also less likely to have access to high-quality health care (Schneider, Zaslavsky, \& Epstein, 2002). Higher rates of COVID-19 infection and mortality among these groups present innumerable sources of stress, including high potential to lose family, friends, and neighbors to the disease, strong risk factors for depression, anxiety, and other mental health problems (Kendler et al., 2003).

Scapegoating of immigrants and other outgroups is common when people seek reassurance while experiencing the threat of disease (Kam, 2019). Thus, racist and xenophobic rhetoric around the origins of the novel coronavirus carries additional risks, particularly for people of Asian ancestry, who have been uniquely scapegoated as carriers of COVID-19. The Asian Pacific Policy and Planning Council (Jeung \& Nham, April 23, 2020) received nearly 1,500 reports of coronavirus discrimination (e.g., stigma, physical attack, suspicion) from Asian Americans across the United States in a 4-week period. Racial discrimination has general adverse physical and mental health effects for Asian Americans (Gee, Ro, Shariff-Marco, \& Chae, 2009), but they are the least likely ethnic group to use mental health services (Smith \& Trimble, 2016), and fear of COVID-19 discrimination may further interfere with help-seeking for physical or mental health problems. Thus, the effects of COVID-19 warrant a response that 
addresses racial/ethnic and socioeconomic disparities broadly, but also one that is specific to the needs of Asian Americans (Hall et al., 2020).

Stigma in the COVID-19 era and beyond. It is highly likely that only a small proportion of those in need of psychological services will receive them, often because they do not seek them. One factor limiting help seeking is ongoing stigmatization of mental health difficulties. Despite far greater public knowledge about mental illness over recent decades, public stigma related to mental and neurodevelopmental disorders remains quite high (Martinez \& Hinshaw, 2016). In the COVID-19 era, with the distinct possibility of real increases in clinically significant anxiety, depression, post-traumatic responses to the pandemic and its sequelae (i.e., financial difficulties, family violence, etc.), how public attitudes and behavioral responses may change is unknown. That is, will the vast shared experience give rise to increased identification, compassion, and acceptance? Or will scapegoating and blaming rise, in terms of not only supposed ethnic origins of the virus, but also the perceived psychological threat that still accompanies perceptions of depressive, disorganized, or potentially violent behavior, during times of deprivation? Past research indicates that stigma rises against disenfranchised outgroups during economic downturns (Hinshaw, 2007).

Optimistically, mental health may come to receive the attention it deserves in the wake of COVID-19. Also, as highlighted elsewhere herein, the necessity of providing mental health care remotely may promote greater access for many, if economic disparities regarding tele- and eaccess are addressed. On the other hand, a core "module" believed to trigger stigmatizing responses is fear of contagion (Goffman, 1963; Kurzban \& Leary, 2001). In an era when literal contagion is on everyone's mind - and when, for valid public health reasons, everyone must try to prevent viral spread — messaging is key. Indeed, 'social distance' is a major target of antistigma interventions, countered largely through contact, disclosure, support, and humanization. 
The public-health term of 'physical distancing' in the COVID era may be less inherently stigmatizing. How amazing it would be if this crisis actually plants seeds for reductions in stigma and enhances the push for prevention, self-care, and treatment.

\section{How Will Treatment Be Conducted?}

For nearly a century, the standard for treatment delivery of psychological services has been a single patient/single provider in a physical office. However, this system has not addressed the population-wide mental health need. In the years preceding COVID-19, up to $67 \%$ of adults and up to $80 \%$ of youths with mental health needs have gone without services each year (Cummings, Wen, \& Druss, 2013; Kessler et al., 2005). Even when services were accessed, many individuals dropped out due to financial and logistical barriers, and provision of evidencebased services remains the exception rather than the rule.

COVID-19 has necessitated a dramatic and immediate change to mental health care delivery that creates important and exciting opportunities to apply clinical psychological science more efficiently and effectively. Below a variety of changes to this standard of care are discussed and opportunities for research and practice to evolve, perhaps well beyond the offset of COVID19 are presented. Clinical psychological scientists are ideally positioned to lead the charge toward a transformation in mental health-care delivery. As new treatment models are developed and deployed, their feasibility, acceptability, benefits, and potential harms will require careful, nuanced evaluation. Clinical psychological scientists possess expertise in many domains key to this goal: program design and evaluation, intervention and implementation science, and mental health care delivery. As such, a roadmap for realizing practical innovation in mental health-care delivery is provided, with the goals of (1) ensuring that a greater proportion of vulnerable individuals, families, and groups gain access to the mental health-care system; and (2) creating more accessible, inclusive avenues to mental health support than have ever existed. 
Telehealth. Seemingly overnight, clinical practice required delivery almost exclusively over telehealth platforms, requiring clinicians to learn and execute HIPAA-compliant video conference systems, identify confidential space to conduct clinical practice within their homes, teach technology to their patients, and examine rapid changes to reimbursement practices to ensure that insurance companies, including Medicare, would reimburse tele-health sessions, including across state lines). In many ways, this modality shift was overdue. Nevertheless, clinical psychological science is now needed to understand a wide array of new variables related to treatment efficacy and effectiveness. For instance, more research is needed on hybrid service provision models, integrating combinations of therapist-, digital/electronic, self-, and layprovider- delivered service components to maximize efficiency of service delivery. Needed investigations include research to determine which telehealth services (i.e., using video, audioonly) are most helpful for individual patients, as well as which patients are most likely to benefit from telehealth relative to more intensive, in-person care. Ultimately, research on these and related questions will permit replacement of "expert consensus" clinical decision-making with empirically driven telemental health practice guidelines. In parallel, research is needed to determine the most effective procedures to conduct valid assessments remotely, including cognitive assessments, observational protocols, and child assessments that may require creative strategies to keep young children engaged without a mutual set of play materials available.

Telehealth also introduces questions regarding the ability to monitor and immediately intervene in high-risk situations. The assessment of imminent suicidality, for instance, or the ability to assist patients with calls to the department of social services in the event of maltreatment, will require modified procedures. Indeed, a formalized, field-wide set of standards for assessing and mitigating imminent risk and monitoring outcomes via telehealth platforms is a high priority. Guidance is needed to work remotely with patients who may develop COVID-19 
during treatment, who may not be able to participate in techniques such as diaphragmatic breathing and progressive muscle relaxation. At least during periods of stay-at-home orders, exposure exercises will be limited as well, given restrictions on interaction outside the home.

The switch to telehealth also has implications for training. Specifically, training programs might consider a wider array of predoctoral internship clinical experiences, not limited to those within a close geographic community. Training to deliver services remotely will require a modification of current practices, and supervision skills similarly may need to be modified. Specifically, training may well require (1) integrating practicum and internship opportunities in telehealth, determining standards for evaluating competence in this domain; (2) prioritizing research on the effectiveness of diverse tele-mental health services; and (3) careful consideration of ethical issues that arise with remote provision of telemental healthcare (e.g., protecting private communication in a globally connected world). Relatedly, in place of the ad-hoc tele-mental health technology systems that clinicians and training programs have implemented in a compressed time period, national technology-system standards for secure, private provision of tele-mental health services are needed. It also is important to increase understanding of - and account for — significant distress experienced by psychologists who provide treatment. Although psychologists are trained to recognize and account for personal issues that may interfere with their ability to meet their patients' needs, the enormous disruptions experienced by all humans (including psychologists), coupled with providers' ethical responsibility to meet the increasing needs of a distressed public, may well create an unusual situation in which typical strategies for self-care may be insufficient.

The switch to telehealth also offers exciting opportunities that may improve clinical psychological science. For instance, telehealth may prompt therapists to utilize technology to collect progress monitoring data and use it to inform treatment, which may lead to better 
outcomes (c.f., Kendrick et al., 2016; Lewis et al., 2018). The expansion of telehealth also offers a solution to address significant disparities in access to mental health treatment, particularly in rural and other areas where few providers reside. Telehealth also creates opportunities to incorporate in-home observational assessments or perhaps even in-vivo exercises into the therapeutic process. Research may further explore the utility of behavioral practice at home, observations of patient's behavior as it occurs, and the provision of immediate feedback in situ.

Brief, Mass-Delivered Interventions. Brief and low-intensity interventions must become a research and clinical practice priority. This includes, as one well-studied example, single-session interventions (SSIs): structured, evidence-based interventions that require just one encounter with a provider or program (Schleider et al., 2020). Evidence suggests that SSIs can reduce or prevent psychopathology in youths and adults (e.g., Schleider et al., 2020; Schleider \& Weisz, 2017), and are effective in treating self-harm (Lamprecht et al., 2007), depressive symptoms (Schleider et al., 2020), and conduct problems (Mejia, Calam, \& Sanders, 2015). Importantly, clinically significant, positive SSI effects emerge even for programs that are selfadministered (e.g., web-based SSIs), without therapist guidance (Schleider \& Weisz, 2017; Schleider et al., 2020). SSIs' overall effects are slightly smaller than those observed for multisession psychotherapy, but their brevity and accessibility magnify their potential public health impact, especially in the case of digital, self-administered SSIs, which are often accessible freeof-charge from any location (e.g., Schleider et al., 2020). Moving ahead, it will be critical to integrate SSIs and other low-intensity interventions into service delivery ecosystems. It will be most helpful to learn from other social and behavioral science fields as to how they have integrated brief interventions, from belongingness interventions that reduce the achievement gap among racial and ethnic minority students to governments using "nudges" to shift unhealthy behaviors (Walton \& Wilson, 2018). Evaluating these approaches will require a "flip" of 
standard research paradigms. Too often, research targets lengthy interventions that include only short-term follow-up assessments, rather than tracking durability of outcomes. Instead, research on short interventions, including SSIs, is needed, as is tracking outcomes for longer follow-up periods. This will provide information regarding which brief interventions have durable effects and which act simply as a prime or state manipulation that would require repetition as the effect fades--akin to an "aspirin" model, wherein taking aspirin helps when one has a headache, but one dose is not expected to prevent all future headaches.

Lay-Provider Service Delivery. An investment and stringent evaluation of scalable layprovider-delivered supports also will be essential. Highly trained clinicians, including clinical psychological scientists, will remain key to flexible, next-generation service provision, but the need for care will continue to outpace demand. Given substantial evidence that nonprofessionals can deliver effective, sensitive, and acceptable care for a diversity of mental health challenges (e.g., Barnett et al., 2018), structures to broaden and formalize lay-provider training are needed. There are impressive non-specialist-provider models from the global mental health field that can help guide work domestically (Singla et al., 2017).

Prevention and Public Health. To address population-wide mental health needs, it will be important for clinical psychological science to look more broadly at strategies and practices to ameliorate or prevent significant psychological distress. In the short run, empirically supported interventions that are readily available and scalable are recommended, and where they do not exist, should be fostered. However, it will be important for the field also to examine interventions that have emerged from outside of clinical psychological science; it is better to focus on solving problems than on "taking credit" for the solutions (Kazdin, 2018). For example, exercise exemplifies a broadly available intervention that benefits mental and physical health, and much more could be done to help ensure it is part of daily life (e.g., in workplaces or 
schools). Research also suggests that contact with nature, including interactions with living systems in the form of greenery, vegetation, and nonhuman animals in open spaces including parks, gardens, and forests, also has been well characterized and has surprisingly robust benefits in both lab studies and randomized controlled trials for depression, anxiety, and social isolation (e.g., Bratman et al., 2019). The field has an opportunity to be more innovative and vigorous in promoting such broadly available interventions, moving beyond usual "lobbying" and "task force reports" to develop concrete action plans, to partner with agencies and foundations to implement, and then to evaluate impact.

In the longer term, clinical psychological science should take a leadership role in preventing or treating clinical and subclinical mental disorders, as well as known risk factors, not by "merely" providing services but by coordinating cross-disciplinary efforts to offer preventive treatment for mental and physical problems. An exciting opportunity for research will be the identification of psychologically active interventions that can be delivered at scale (cf. fluoride in the water) to build resilience and reduce risks among large segments of the population that may never find their way to a traditional psychotherapy session. Fortunately, alternative models of good treatment delivery already exist in other fields (e.g., public health, law, social policy, business, entertainment) and may help to provide larger scale treatment. Similarly, many sectors of society (e.g., primary, secondary, and higher education systems, corporate human resource centers, justice and correctional systems) are increasingly interested in mental health wellness, and many new industries (e.g., technological tools, genetic/ancestry tracing) are willing partners to help advance clinical psychological science and its applications.

\section{How Best To Evaluate These New Approaches?}

Of course, new approaches to psychological service delivery will require careful empirical examination. For instance, research on resilience trajectories and stepped-care models 
will be critical to determining who can be served adequately with lower- versus higher-intensity treatments. Partnership with lay providers will require far greater community involvement, training programs to teach students how to partner with community leaders (e.g., faith leaders, social justice advocates), providers, and persons with lived experience so that interventions are ultimately acceptable to communities, fit their context, and address outcomes they value. Primary prevention approaches will require collaboration with new disciplines, including forprofit industries, that will utilize different methodological approaches and collect data with different priorities and values that may require methodological compromises. Yet, these adaptations may be necessary to change clinical psychological science in fundamental ways needed to meet the new demands of COVID-19 and its aftermath.

Already, scientists have begun to experience the challenge of research relying on the status quo. Obviously, human subjects research has been challenging during COVID-required physical distancing. Some methods - physiological measurement, experience sampling — have already lent themselves to ambulatory techniques. Additionally, interviews can often be conducted by video or phone. Questionnaires can be administered through online systems like Qualtrics. Psychosocial interventions can be conducted via telemedicine approaches, and behavior observation tasks can be carried in the home via video. Importantly, such remote methods may be compatible with the increasingly socially oriented research questions, which as noted further below, are particularly relevant in the COVID era. When lab-based methods are used (e.g., MRI scanning), there must be allowances for physical distancing with participants and among research staff (e.g., staggering work schedules). Further, COVID-19 must be met with increased cooperation and innovations in the process of scientific discourse. Collaborations will be critical to pooling resources to mine existing data and collect new data quickly. New findings will then need both rapid dissemination (e.g., at this writing, over 300 pre-prints of COVID-19 
projects are circulating) and careful evaluation. There is a critical needle to thread: how can scientific peer-review be accelerated to accommodate the urgency of studying COVID-19, while maintaining the quality of the vetting process?

Conceptually, COVID-19 has laid bare the interconnectedness of so many aspects of human existence - of humans with one another; of social and economic systems and institutions; of structural inequities with adaptive functioning; of mental with physical health. In this way, the pandemic spotlights the need for a multi-dimensional understanding of human adaptation. Clinical psychological science must embrace this complexity and seek to understand the impact and inequities of COVID-19 within an interactional, intersectional, and interdisciplinary framework. Relatedly, it will be important to learn whether existing interventions — which may already be evidence-based in other contexts - can also reduce the burden of mental health related to the intersecting challenges of COVID-19. Existing interventions may require adaptations to help recipients build resilience in the COVID-19 context. Additionally, because COVID-19 affects functioning in many bodily systems, it will be valuable to delineate how the disease influences mental health via neurobiological, cardiovascular, respiratory, and other changes. Even more, clinical psychological science will need to reconcile the complementary strengths of psychiatric, disease-oriented perspectives on mental illness with perspectives locating causes of suffering within the social ecology. In sum, clinical psychological science research must rise to the occasion and learn from this moment to increase the versatility of both its methods and conceptual perspectives.

\section{Concluding Comments}

Clinical psychological science is needed more than ever in response to both the acute and enduring psychological effects of COVID-19 (Ghebreyesus, 2020). This paper is intended to inspire dialogue surrounding the challenges the field faces and how it must adapt to meet the mental health demands of a rapidly evolving psychological landscape. Of course, sustained 
change will require strong advocacy to ensure that mental health research funding is available to understand and address mental health challenges following COVID-19. To secure a leadership role, clinical psychological scientists must be prepared to raise their voices not only within scientific outlets, but also in public discussions on the airwaves (radio, cable news), alongside colleagues in other scientific fields. Sustained effort, collaboration with other disciplines, and unity within psychology will be necessary to address the multi-faceted impacts of COVID-19 on humanity.

\section{References}

Albee, G.W. (1970). The uncertain future of clinical psychology. American Psychologist, 25, 1071-1080.

Adhanom Ghebreyesus, T. (2020). Addressing mental health needs: an integral part of COVID19 response. World Psychiatry, 19(2), 129-130. doi: 10.1002/wps.20768

Alexander, G. C., Stoller, K. B., Haffajee, R. L., \& Saloner, B. (2020). An epidemic in the midst of a pandemic: Opioid use disorder and COVID-19. Annals of Internal Medicine. doi:10.7326/M20-1141 
Aldao, A., \& Nolen-Hoeksema, S. (2010). Specificity of cognitive emotion regulation strategies: A transdiagnostic examination. Behaviour Research and Therapy, 48, 974-983. doi: 10.1016/j.brat.2010.06.002

Alisic, E., Zalta, A.K., van Wesel, F., Larsen, S.E., Hafsted, G.S., Hassanpour, K., \& Smid, G.E. (2014). Rates of post-traumatic stress disorder in trauma exposed children and adolescents: Meta-analysis. The British Journal of Psychiatry, 204, 335-340.

American Psychological Association. (2020). Telehealth guidance by state during COVID-19: State emergency orders relevant to licensed psychologists during the COVID-19 public health crisis. Retrieved from: https://www.apaservices.org/practice/clinic/covid-19telehealth-state-summary?_ga=2.7791794.1068186990.15900151931603345642.1590015193

American Psychological Association. (2017). Clinical practice guideline for the treatment of Posttraumatic Stress Disorder (PTSD) in adults. Washington, DC: American Psychological Association.

Armitage, R., \& Nellums, L.B. (2020). COVID-19 and the consequences of isolating the elderly. The Lancet Public Health. doi: /10.1016/S2468-2667(20)30061-X

Arnett, J. J. (2014). Emerging adulthood: The winding road from the late teens through the twenties. Oxford, UK: Oxford University Press.

Barnett, M. L., Lau, A. S., \& Miranda, J. (2018). Lay health worker involvement in evidencebased treatment delivery: A conceptual model to address disparities in care. Annual Review of Clinical Psychology, 14, 185-208. doi: 10.1146/annurev-clinpsy-050817-084825

Belvederi Murri, M., Prestia, D., Mondelli, V., et al. (2016). The HPA axis in bipolar disorder: Systematic review and meta-analysis. Psychoneuroendocrinology. 2016;327-342. doi:10.1016/j.psyneuen.2015.10.014 
Bonanno, G. A., Brewin, C. R., Kaniasty, K., \& La Greca, A. M. (2010). Weighing the costs of disaster: Consequences, risks, and resilience in individuals, families, and communities. Psychological Science in the Public Interest, 11(1), 1-49.

Bootzin, R. R., \& Bailey, E. T. (2005). Understanding placebo, nocebo, and iatrogenic treatment effects. Journal of Clinical Psychology, 61(7), 871-880.

Bratman, G. N., Anderson, C. B., Berman, M. G., Cochran, B., De Vries, S., Flanders, J., ... \& Kahn, P. H. (2019). Nature and mental health: An ecosystem service perspective. Science Advances, 5(7), eaax0903.

Brooks, S. K., Webster, R. K., Smith, L. E., Woodland, L., Wessely, S., Greenberg, N., \& Rubin, G. J. (2020). The psychological impact of quarantine and how to reduce it: rapid review of the evidence. The Lancet.

Brown, J., Cohen, P., Johnson, J., \& Salzinger, S. (1998). A longitudinal analysis of risk factors for child maltreatment: findings of a 17-year prospective sutdy of officially recorded and self-reported child abuse and neglect. Child Abuse and Neglect, 22, 1065-1078.

Brymer, M., Jacobs, A., Layne, C., Pynoos, R., Ruzek, J., Steinberg, A., Vernberg, E., \& Watson, P. (2006). Psychological First Aid (PFA): Field operations guide (2nd Ed.). National Child Traumatic Stress Network and National Center for PTSD. Retrieved from: https://www.ptsd.va.gov/professional/treat/type/PFA/PFA_2ndEditionwithappendices.pdf

Cacioppo, S., Grippo, A. J., London, S., Goossens, L., \& Cacioppo, J. T. (2015). Loneliness: Clinical import and interventions. Perspectives on Psychological Science, 10(2), 238-249. doi: $10.1177 / 1745691615570616$

Claassen, C. A., Carmody, T., Stewart, S. M., Bossarte, R. M., Larkin, G. L., Woodward, W. A., 
\& Trivedi, M. H. (2010). Effect of 11 September 2001 terrorist attacks in the USA on suicide in areas surrounding the crash sites. The British Journal of Psychiatry, 196(5), $359-364$.

Cohen, S. (2004). Social relationships and health. American Psychologist, 59, 676-684.

Cohen, J.A. and the Workgroup on Quality Issues. (2010). Practice parameters for the assessment and treatment of children and adolescents with PTSD. Journal of the American Academy of Child and Adolescent Psychiatry, 49, 414-430.

Compas, B. E., Jaser, S. S., Bettis, A. H., Watson, K. H., Gruhn, M. A., Dunbar, J. P., . . . Thigpen, J. C. (2017). Coping, emotion regulation, and psychopathology in childhood and adolescence: A meta-analysis and narrative review. Psychological Bulletin, 143, 939-991.

Cooper, H., Nye, B., Charlton, K., Lindsay, J., \& Greathouse, S. (1996). The effects of summer vacation on achievement test scores: A narrative and meta-analytic review. Review of Educational Research, 66, 227-268.

Corcoran, C., Walker, E., Huot, R., Mittal, V., Tessner, K., Kestler, L., \& Malaspina, D. (2003). The stress cascade and schizophrenia: etiology and onset. Schizophrenia Bulletin, 29(4), $671-692$.

Cummings, J. R., Wen, H., \& Druss, B. G. (2013). Improving access to mental health services for youth in the United States. JAMA, 309(6), 553-554.

Duarte, C.S., Hoven, C.W., Wu, P., et al. (2006). Posttraumatic stress in children with first responders in their families. Journal of Trauma Stress, 19(2), 301-306.

Evans, G. W., \& Kim, P. (2010). Multiple risk exposure as a potential explanatory mechanism for the socioeconomic status-health gradient. Annals of the New York Academy of Sciences, $1186,174-189$. 
Farmer, E. M., Burns, B. J., Phillips, A., Angold, A., \& Costello, E. J. (2003). Pathways into and through mental health services for children and adolescents. Psychiatric Services, 54, 6066.

Fazel, S., Yoon, I. A., \& Hayes, A. J. (2017). Substance use disorders in prisoners: an updated systematic review and meta-regression analysis in recently incarcerated men and women. Addiction, 112(10), 1725-1739. doi:10.1111/add.13877

Forbes, E. E. \& Dahl, R. E. (2012). Altered reward function in adolescent depression: what, when and how? Journal of Child Psychology and Psychiatry, 53(1), 3-15.

Furman, D., Campisi, J., Verdin, E., Carrera-Bastos, P., Targ, S., Franceschi, C., Ferrucci, L., Gilroy, D. W., Fasano, A., Miller, G. W., Miller, A. H., Mantovani, A., Weyand, C. M., Barzilai, N., Goronzy, J. J., Rando, T. A., Effros, R. B., Lucia, A., Kleinstreuer, N., \& Slavich, G. M. (2019). Chronic inflammation in the etiology of disease across the life span. Nature Medicine, 25, 1822-1832. doi: 10.1038/s41591-019-0675-0

Galatzer-Levy, I. R., Huang, S. H., \& Bonanno, G. A. (2018). Trajectories of resilience and dysfunction following potential trauma: A review and statistical evaluation. Clinical Psychology Review, 63, 41-55. doi: 10.1016/j.cpr.2018.05.008

Garnier-Crussard, A., Forestier, E., Gilbert, T., \& Krolak-Salmon, P. (2020). Novel coronavirus (COVID-19) epidemic: What are the risks for older patients? Journal of the American Geriatric Society. doi: 10.1111/jgs.16407

Gao, J., Zheng, P., Jia, Y., Chen, H., Mao, Y., Chen, S., et al. (2020). Mental health problems and social media exposure during COVID-19 outbreak. PLoS ONE 15(4): e0231924.

Gawęda, Ł., Pionke, R., Krężołek, M., Frydecka, D., Nelson, B., \& Cechnicki, A. (2020). The interplay between childhood trauma, cognitive biases, psychotic-like experiences and 
depression and their additive impact on predicting lifetime suicidal behavior in young adults. Psychological Medicine, 50(1), 116-124.

Ghebreyesus, T. A. (2020). Addressing mental health needs: An integral part of COVID-19 response. World Psychiatry, 19(2), 129-130.

Gee, D. G., Gabard-Durnam, L., Telzer, E. H., Humphreys, K. L., Goff, B., ... Tottenham, N. (2014). Maternal buffering of human amygdala-prefrontal circuitry during childhood but not during adolescence. Psychological Science, 25(11), 2067-2078. doi: $10.1177 / 0956797614550878$

Gee, G. C., Ro, A., Shariff-Marco, \& Chae, D. (2009). Racial discrimination and health among Asian Americans: Evidence, assessment, and directions for future research. Epidemiologic Reviews, 31, 130-151. doi: 10.1093/epirev/mxp009

Goffman, E. (1963). Stigma: Notes on the management of spoiled identity. Englewood Cliffs, NJ: Prentice Hall.

Gold, K. J., Sen, A., \& Schwenk, T. L. (2013). Details on suicide among US physicians: data from the National Violent Death Reporting System. General Hospital Psychiatry, 35(1), 45-49.

Gray, J. A. (1990). Brain systems that mediate both emotion and cognition. Cognition and Emotion, 4, 269-288. doi : 10.1080/02699939008410799

Greenberg, N. \& Docherty, M. (2020). Managing mental health challenges faced by healthcare workers during COVID-19 pandemic. BMJ, 368, m1211.

Greinacher, A., Derezza-Greeven, C., Herzog, W., \& Nikendei, C. (2019). Secondary traumatization in first responders: a systematic review. European Journal of Psychotraumatology, 10(1), 1562840. doi: 10.1080/20008198.2018.1562840 
Griffin, B. J., Purcell, N., Burkman, K., Litz, B. T., Bryan, C. J., Schmitz, M., ... \& Maguen, S. (2019). Moral injury: An integrative review. Journal of Traumatic Stress, 32(3), 350-362.

Gross, J. J., \& Jazaieri, H. (2014). Emotion, emotion regulation, and psychopathology: An affective science perspective. Clinical Psychological Science, 2, 387-401. doi: $10.1177 / 2167702614536164$

Gruber, J. \& Rottenberg, J. (2020). Flattening the mental health curvey is the next big coronavirus challenge. Retrieved from: https://theconversation.com/flattening-the-mentalhealth-curve-is-the-next-big-coronavirus-challenge-139066

Hall, G. C. N., Berkman, E. T., Zane, N. W., Leong, F. T. L., Hwang, W.-C., Nezu, A. M., Nezu, C. M., Hong, J. J., Chu, J. P., \& Huang, E. R. (2020). Reducing mental health disparities by increasing the personal relevance of interventions. American Psychologist. Advance online publication. doi: 10.1037/amp0000616

Hatch, R., Young, D., Barber, V., Griffiths, J., Harrison, D.A., \& Watkinson, P. (2018). Anxiety, depression and post traumatic stress disorder after critical illness: A UK-wide prospective cohort study. Critical Care, 22(1), 310. doi:10.1186/s13054-018-2223-6

Hinshaw, S. P. (2007). The mark of shame: Stigma of mental illness and an agenda for change. New York: Oxford University Press.

Hofmann, S. G. (2014). Interpersonal emotion regulation model of mood and anxiety disorders. Cognitive Therapy and Research, 38, 483-492. doi: 10.1007/s10608-014-9620-1

Hofmann, S. G., Sawyer, A. T., Fang, A., \& Asnaani, A. (2012). Emotion dysregulation model of mood and anxiety disorders. Depression and Anxiety, 29, 409-416. doi: 10.1002/da.21888. 
Holmes, E. A., O-Connor, R. C., Perry, V. H., Tracey, I., Wessley, S., ... Bullmore, E. (2020). Multidisciplinary research priorities for the COVID-19 pandemic: A call for action for mental health science. Lancet Psychiatry. doi: 10.1016/S2215-0366(20)30168-1

Jansen, N. W., Kant, I., Kristensen, T. S., \& Nijhuis, F. J. (2003). Antecedents and consequences of work-family conflict: A prospective cohort study. Journal of Occupational and Environmental Medicine, 45(5), 479-491. doi:10.1097/01.jom.0000063626.37065.e8

Jeung, R., \& Nham, K. (April 23, 2020). Incidents of coronavirus-related discrimination. Asian Pacific Policy and Planning Council. Retrieved from: http://www.asianpacificpolicyandplanningcouncil.org/wpcontent/uploads/STOP_AAPI_HATE_MONTHLY_REPORT_4_23_20.pdf

Johns Hopkins COVID-19 Mental Health Measurement Working Group. (2020). Measuring Mental Distress Amid a Pandemic: Understanding COVID-19's Psychological Effects Over Time. Retrieved from https://www.jhsph.edu/covid-19/articles/measuring-mentaldistress-amid-a-pandemic.html

Kam, C. D. (2019). Infectious disease, disgust, and imagining the other. The Journal of Politics, 81, 1371-1387. doi:10.1086/704438

Kaniasty K. \& Norris, F.H . (2008). Longitudinal linkages between perceived social support and posttraumatic stress symptoms: sequential roles of social causation and social selection. Journal of Traumatic Stress, 21(3), 274-281. doi:10.1002/jts.20334

Kang, L., Li, Y., Hu, S., Chen, M., Yang, C., Yang, B., et al. (2020). The mental health of medical workers in Wuhan: China dealing with the 2019 novel coronavirus. Lancet, 7, E14. Kazdin, A.E. (2018). Innovations in psychosocial interventions and their delivery: Leveraging cutting-edge science to improve the world's mental health. New York: Oxford University Press. 
Kendler, K. S., Hettema, J. M., Butera, F., Gardner, C. O., \& Prescott, C. A. (2003). Life event dimensions of loss, humiliation, entrapment, and danger in the prediction of onsets of major depression and generalized anxiety. Archives of General Psychiatry, 60, 789-796.

Kessler, R.C., Demler, O., Frank, R.G., Olfson, M., Pincus, H.A., Walters, E.E., ... Zaslavsky, A.M. (2005). Prevalence and treatment of mental disorders, 1990 to 2003. New England Journal of Medicine, 352, 2515-2523.

Khatri, U. G., \& Perrone, J. (2020). Opioid Use Disorder and COVID-19: Crashing of the crises. Journal of Addiction Medicine. doi: 10.1097/adm.0000000000000684

Kinnunen, U., \& Mauno, S. (1998). Antecedents and outcomes of work-family conflict among employed women and men in Finland. Human Relations, 51(2), 157-177. doi: $10.1177 / 001872679805100203$

Kõlves, K., Kõlves, K. E., \& De Leo, D. (2013). Natural disasters and suicidal behaviours: a systematic literature review. Journal of Affective Disorders, 146(1), 1-14.

Kratochvil, C.J., Evans, L., Ribner, B.S., Lowe, J.J., Harvey, M.C., ... Smith, P. (2017). The National Ebola Training and Education Center: Preparing the United States for ebola and other special pathogens. Health Security, 15(3), 253-260.

Kujawa, A., Hajcak, G., Danzig, A.P., Black, S.R., Bromet, E.J., Carlson, G.A., Kotov, R., \& Klein. D. N. (2016). Neural reactivity to emotional stimuli prospectively predicts the impact of a natural disaster on psychiatric symptoms in children. Biological Psychiatry, 80, $381-389$.

Kurzban, R., \& Leary, M. R. (2001). Evolutionary origins of stigmatization: The functions of social exclusion. Psychological Bulletin, 127, 187-208. 
La Greca, A.M., \& Danzi, B.A. (2019). Posttraumatic stress disorder. In M.J. Prinstein, E.A., Youngstrom, E.J. Mash, and R.A. Buckley (Eds.), Treatment of childhood disorders (4th Ed.). New York, NY: Guilford Press.

La Greca, A. M., Silverman, W. K., Vernberg, E. M., \& Roberts, M. C. (Eds.). (2002). Helping children cope with disasters and terrorism. Washington, DC: American Psychological Association.

Lai, J., Ma, S., Wang, Y., Cai, Z., Hu, J., Wei, N., ... \& Tan, H. (2020). Factors associated with mental health outcomes among health care workers exposed to coronavirus disease 2019. JAMA Network Open, 3(3), e203976-e203976.

Lai, B. S., La Greca, A. M., Auslander, B. A., \& Short, M. B. (2013). Children's symptoms of posttraumatic stress and depression after a natural disaster: Comorbidity and risk factors. Journal of Affective Disorders, 146, 71-78.

Lamprecht, H., Laydon, C., McQuillan, C., Wiseman, S., Williams, L. Y. N., Gash, A., \& Reilly, J. O. E. (2007). Single-session solution-focused brief therapy and self-harm: A pilot study. Journal of Psychiatric and Mental Health Nursing, 14, 601-602.

Lancee, W. J., Maunder, R. G., \& Goldbloom, D. S. (2008). Prevalence of psychiatric disorders among Toronto hospital workers one to two years after the SARS outbreak. Psychiatric Services, 59(1), 91-95.

Lazarus, R., \& Folkman, S. (1984). Stress, appraisal and coping. New York: Springer.

Lewis, C. C., Boyd, M., Puspitasari, A., Navarro, E., Howard, J., Kassab, H., . . Douglas, S. (2018). Implementing measurement-based care in behavioral health: A review. JAMA Psychiatry, 76(3), 324-335. 
Lung, F. W., Lu, Y. C., Chang, Y. Y., \& Shu, B. C. (2009). Mental symptoms in different health professionals during the SARS attack: A follow-up study. Psychiatric Quarterly, 80(2), 107-116.

Manjoo, F.. (April 22, 2020). Two parents. Two kids. Two jobs. No childcare. New York Times. Retrieved from: https://www.nytimes.com/2020/04/22/opinion/coronavirus-parentingburnout.html

Martikainen, S., Pesonen, A.-K., Lahti, J., Heinonen, K., Feldt, K., Pyhala, R., . . Raikkonen, K. (2013). Higher levels of physical activity are associated with lower hypothalamic-pituitaryadrenocortical axis reactivity to psychosocial stress in children. Journal of Clinical Endocrinology \& Metabolism, 98, E619-E627.

Martinez, A., \& Hinshaw, S. P. (2016). Mental health stigma: Theory, developmental issues, and research priorities. In D. Cicchetti (Ed.), Developmental psychopathology. Vol 4: Risk, resilience, and intervention (3rd ed., pp. 997-1039). Hoboken, NJ: Wiley.

McEwen, B. S. \& Stellar, E (1993). Stress and the individual. Mechanisms leading to disease. Archives of Internal Medicine, 153, 2093-101. doi:10.1001/archinte.153.18.2093

McEwen, B. S \& Wingfield, J. C (2003). The concept of allostasis in biology and biomedicine. Hormones and Behavior, 43, 2-15. doi:10.1016/S0018-506X(02)00024-7.

McLaughlin, K. A., Conron, K. J., Koenen, K. C., \& Gilman, S. E. (2010). Childhood adversity, adult stressful life events, and risk of past-year psychiatric disorder: A test of the stress sensitization hypothesis in a population-based sample of adults. Psychological Medicine, $40,1647-1658$.

McLaughlin, K. A., Green, J. G., Alegria, M., Costello, E. J., Gruber, M., Sampson, N. A., \& Kessler, R. C. (2012). Food insecurity and past-year mental disorders in a national sample 
of U.S. adolescents. Journal of the American Academy of Child \& Adolescent Psychiatry, $51,1293-1303$.

McLaughlin, K. A., Green, J. G., Gruber, M. J., Sampson, N. A., Zaslavsky, A., \& Kessler, R. C. (2012). Childhood adversities and first onset of psychiatric disorders in a national sample of adolescents. Archives of General Psychiatry, 69, 1151-1160.

Mejia, A., Calam, R., \& Sanders, M. R. (2015). A pilot randomized controlled trial of a brief parenting intervention in low-resource settings in Panama. Prevention Science, 16(5), 707717.

Merikangas, K. R., He, J. P., Burstein, M., Swendsen, J., Avenevoli, S., Case, B., . . Olfson, M. (2011). Service utilization for lifetime mental disorders in US adolescents: results of the National Comorbidity Survey-Adolescent Supplement (NCS-A). Journal of the American Academy of Child \& Adolescent Psychiatry, 50, 32-45.

Meyer, A., Danielson, C., Danzig, A.P., Bhatia, V., Black, S.R., Bromet, E., Carlson, G.A., Hajcak, G., Kotov, R., \& Klein, D.N. (2017). Neural biomarker and early temperament predict increased internalizing symptoms after a natural disaster. Journal of the American Academy of Child and Adolescent Psychiatry, 56, 410-416.

Miller, A. B., \& Prinstein, M. J. (2019). Adolescent Suicide as a Failure of Acute Stress Response Systems. Annual Review of Clinical Psychology, 15, 425-450. doi: 0.1146/annurev-clinpsy-050718- 095625

Monroe, S. M. (2008). Modern approaches to conceptualizing and measuring human life stress. Annual Review of Clinical Psychology, 4, 33-52.

Nagelhout, G. E., Hummel, K., de Goeij, M. C. M., de Vries, H., Kaner, E., \& Lemmens, P. (2017). How economic recessions and unemployment affect illegal drug use: A systematic 
realist literature review. International Journal of Drug Policy, 44, 69-83. doi

10.1016/j.drugpo.2017.03.013

Nock, M. K., \& Kessler, R. C. (2006). Prevalence of and risk factors for suicide attempts versus suicide gestures: Analysis of the National Comorbidity Survey. Journal of Abnormal Psychology, 115(3), 616.

Nolen-Hoeksema, S., Wisco, B. E., \& Lyubomirsky, S. (2008). Rethinking rumination. Perspectives on Psychological Science, 3, 400-424.

Norris, F. H., Friedman, M. J., Watson, P. J., Byrne, C. M., Diaz, E., \& Kaniasty, K. (2002). 60,000 disaster victims speak: Part I. An empirical review of empirical literature, 19812001. Psychiatry: Interpersonal and Biological Processes, 65, 207-239.

O’Donovan, A., Slavich, G. M., Epel, E. S., \& Neylan, T. C. (2013). Exaggerated neurobiological sensitivity to threat as a mechanism linking anxiety with increased risk for diseases of aging. Neuroscience and Biobehavioral Reviews, 37, 96-108. doi:

10.1016/j.neubiorev.2012.10.013

Oltmanns, T. F., \& Krasner, L. (1993). A voice for clinical science in clinical psychology: The history of Section III of Division 12. The Clinical Psychologist, 46 (1), 25-32. Retrieved from: https://sites.google.com/site/sscpwebsite/Home/history-of-sscp\#return3

Prinstein M. J. \& Giletta, M. (2016). Peer relations and developmental psychopathology. In D. Cicchetti, (Ed.), Developmental Psychopathology, Third Edition (Volume 1, pp. 527-579). Hoboken, NJ: Wiley.

Reeves, A., Stuckler, D., McKee, M., Gunnell, D., Chang, S. S., \& Basu, S. (2012). Increase in state suicide rates in the USA during economic recession. The Lancet, 380(9856), 18131814. 
Sareen, J. (2014). Posttraumatic stress disorder in adults: Impact, comorbidity, risk factors, and treatment. The Canadian Journal of Psychiatry, 59(9), 460-467.

Schleider, J. L., Dobias, M. L., Sung, J. Y., \& Mullarkey, M. C. (2020). Future directions in single-session youth mental health interventions. Journal of Clinical Child and Adolescent Psychology, 2, 264-278.

Schleider, J. L., \& Weisz, J. R. (2017). Little treatments, promising effects? Meta-analysis of single session interventions for youth psychiatric problems. Journal of the American Academy of Child \& Adolescent Psychiatry, 56, 107-115.

Segerstrom, S. C., Tsao, J. C. I., Alden, L. E., \& Craske, M. G. (2000). Worry and rumination: Repetitive thought as a concomitant and predictor of negative mood. Cognitive Therapy and Research, 24, 671-688.

Singh, G. K., \& Siahpush, M. (2006). Widening socioeconomic inequalities in US life expectancy, 1980-2000. International Journal of Epidemiology, 35, 969-979.

Singla, D. R., Kohrt, B. A., Murray, L. K., Anand, A., Chorpita, B. F., \& Patel, V. (2017). Psychological treatments for the world: Lessons from low-and middle-income countries. Annual Review of Clinical Psychology, 13, 149-181.

Slavich, G. M. (2020). Social safety theory: A biologically based evolutionary perspective on life stress, health, and behavior. Annual Review of Clinical Psychology, 16, 265-295. doi: 10.1146/annurev-clinpsy-032816-045159

Slavich, G. M., \& Irwin, M. R. (2014). From stress to inflammation and major depressive disorder: A social signal transduction theory of depression. Psychological Bulletin, 140, 774-815. doi: $10.1037 / \mathrm{a} 0035302$

Smith, J. C., Sausville, E. L., Girish, V., Yuan, M. L., Vasudevan, A., John, K. M., \& Sheltzer, J. M. (2020). Cigarette smoke exposure and inflammatory signaling increase the expression of 
the SARS-CoV-2 receptor ACE2 in the respiratory tract. Developmental Cell. doi:

10.1016/j.devcel.2020.05.012

Smith, T. B., \& Trimble, J. E. (2016). Foundations of multicultural psychology: Research to inform effective practice. Washington, DC: American Psychological Association. doi: $10.1037 / 14733-000$

Soloman, D., Maxwell, C., \& Castro, A. (2019). Systematic inequality and economic opportunity. Center for American Progress. Retrieved from https://www.americanprogress.org/issues/race/reports/2019/08/07/472910/systematicinequality-economic-opportunity/

Stoltenborgh, M., Bakermans-Kranenburg, M. J., \& Van Ijzendoorn, M. H. (2013). The neglect of child neglect: a meta-analytic review of the prevalence of neglect. Social Psychiatry and Psychiatric Epidemiology, 48, 345-355.

Tessner, K.D., Mittal, V., \& Walker, E.F. (2011). Longitudinal study of stressful life events and daily stressors among adolescents at high risk for psychotic disorders. Schizophrenia Bulletin, 37(2), 432-441.

Van Lancker, W., \& Parolin, Z. (2020). COVID-19, school closures, and poverty: A social crisis in the making. Lancet Public Health, 5(5), e243-e244. doi: 10.1016/S2468-2667(20)300840

Wang, H., Li, T., Barbarino, P., Gauthier, S., Brodaty, H, Molinuevo... Yu, X. (2020). Dementia care during COVID-19. The Lancet. doi:10.1016/S0140-6736(20)30755-8

Walton, G. M. \& Wilson, T. D. (2018). Wise interventions: Psychological remedies for social and personal problems. Psychological Review, 125(5), 617-655. doi: 10.1037/rev0000115

Walker, E. F. \& Diforio, D. (1997). Schizophrenia: a neural diathesis-stress model. Psychological Review, 104(4), 667-685. 
Wasserman, I. M. (1992). The impact of epidemic, war, prohibition and media on suicide: United States, 1910-1920. Suicide and Life-Threatening Behavior, 22(2), 240-254.

Williams, J., Gonzalez-Medina, D., \& Le, Q. (2011). Infectious diseases and social stigma. Applied Technologies and Innovations, 4, 58-70.

World Health Organization Coronavirus Disease [COVID-19] Dashboard. Retrieved on June 14 https://covid19.who.int/?gclid=CjwKCAjwlZf3BRABEiwA8Q0qq0CqtiK3eUET8rSMqff7 Yszf8NEv7WVmU18OP8oG2kQ0SfZIoq4PIhoC-18QAvD_BwE

Xie, X., Xue, Q., Zhou, Y., Zhu, K., Liu, Q., Zhang, J., \& Song, R. (2020). Mental health status among children in home confinement during the coronavirus disease 2019 outbreak in Hubei Province, China. JAMA Pediatrics. doi: 0.1001/jamapediatrics.2020.1619

Zephyrin, L., Radley, D.C., Getachew, Y., Baumgartner, J.C., \& Schneider, E.C. (2020, April 23). COVID-19 more prevalent, deadlier in U.S. counties with higher Black populations. The Commonwealth Fund. Retrieved from: https://www.commonwealthfund.org/blog/2020/covid-19-more-prevalent-deadlier-uscounties-higher-black-populations 